\title{
PERSPEKTIF PENGEMBANGAN PERIKANAN BUDIDAYA BERDASARKAN KARAKTERISTIK PANTAI DI TELUK GERUPUK DAN TELUK BUMBANG KABUPATEN LOMBOK TENGAH PROVINSI NUSA TENGGARA BARAT
}

\author{
Tarunamulia”, Hasnawi, Rezki Antoni Suhaimi, Akhmad Mustafa, dan Mudian Paena \\ Balai Penelitian dan Pengembangan Budidaya Air Payau
}

(Naskah diterima: 14 Oktober 2014; Revisi final: 8 Februari 2015; Disetujui publikasi: 11 Maret 2015)

\begin{abstract}
ABSTRAK
Tersedianya informasi mengenai karakteristik pantai menjadi salah satu faktor penentu keberhasilan perencanaan dan pengelolaan perikanan budidaya pesisir berbasis lahan. Penelitian ini bertujuan untuk mengetahui karakteristik pantai khususnya aspek topografi dan hidrologi di Teluk Gerupuk dan Teluk Bumbang Kecamatan Pujut Kabupaten Lombok Tengah Provinsi Nusa Tenggara Barat (NTB), hubungannya dengan status eksisting dan kemungkinan pengembangan perikanan budidaya. Variabel topografi dan hidrologi teluk yang diukur meliputi: pasang surut (pasut), kedalaman, dan kelandaian pantai. Hasil analisis menunjukkan bahwa karakteristik pasut dengan tunggang pasut sekitar 2,85 m secara teknis masih tergolong ideal untuk pengembangan berbagai sistem budidaya tambak udang (tradisional plus, semi-intensif, intensif, dan super-intensif). Khusus untuk tambak intensif dan super-intensif, tunggang pasut yang besar harus dicermati sehubungan dengan jauhnya jarak pengambilan air bersih. Secara umum Teluk Gerupuk dan Teluk Bumbang dengan luas \pm 940 ha $\left(9,4 \mathrm{~km}^{2}\right)$ dan kedalaman rata-rata perairan 4,17 $\pm 0,12$ cukup mendukung untuk kegiatan budidaya rumput laut. Berkembangnya pemanfaatan lahan selain budidaya rumput laut di sekitar dan pada teluk seperti pemukiman, pariwisata, dan budidaya tambak, dapat memengaruhi kualitas kimia fisik perairan dan kemungkinan berkaitan erat dengan menurunnya produksi rumput laut pada tahun-tahun terakhir. Dengan batasan karakteristik topografi dan hidrologis teluk yang menjadi pusat berlabuhnya aktivitas penggunaan lahan pantai dan darat, dibutuhkan perhatian serius mengenai rencana umum tata ruang wilayah teluk termasuk penanganan limbah agar tidak berdampak negatif secara ekologis dan sosial yang pada akhirnya akan mengganggu keberlanjutan usaha perikanan budidaya di wilayah ini.
\end{abstract}

KATA KUNCI: hidrologi, topografi, perikanan budidaya, Teluk Gerupuk, Nusa Tenggara Barat

ABSTRACT: Perspective on aquaculture development based upon coastal physical characteristics in Gerupuk and Bumbang Bays Central Lombok Regency West Nusa Tenggara Province. By: Tarunamulia, Hasnawi, Rezki Antoni Suhaimi, Akhmad Mustafa, and Mudian Paena

A better understanding of the coastal physical characteristics is critically important to achieve the long-term success of coastal aquaculture management. The objective of this study was to understand the coastal physical characteristics particularly topography and hydrology with reference to the status of coastal aquaculture development in Gerupuk and Bumbang Bays Central Lombok Regency West Nusa Tenggara Province. The measured coastal topographic and hydrological variables included tide, water depth, and coast or beach slope. The results indicated that with a tidal range of $2.85 \mathrm{~m}$, it is technically suitable for most brackishwater pond aquaculture technologies i.e. extensive plus, semiintensive, intensive, and super-intensive. However, for intensive and super-intensive aquaculture, this tidal range will potentially require high investment to bring adequate sea water from supply source. Additionally, having the total water area of about $940 \mathrm{ha}\left(9.4 \mathrm{~km}^{2}\right)$ and average water depth of $4.17 \pm 0.12$, the study area is generally considered to be a suitable location for seaweed (Kappaphycus alvarezii) culture. The rapid change and development of land uses other than for seaweed culture in the study area such as residential, tourism industry, and agriculture, could lead to the change in physio-chemical properties of the waters that exceed the state water quality criterion, and possibly

\# Korespondensi: Balai Penelitian dan Pengembangan Budidaya

Air Payau. Jl. Makmur Dg. Sitakka No. 129, Maros 90512,

Sulawesi Selatan, Indonesia. Tel.: + (0411) 371544; 371545

E-mail: tarunamulia@yahoo.com 
become the major cause of the decline in seaweed production in recent years. Hence, considering the topographical and hydrological limitations to accommodate different types of land use, the study area requires the availability of effective coastal area management, including of waste management plans so as not to negatively impact the ecological and social sustainability of the existing coastal industries, including aquaculture.

KEYWORDS: hydrology, topography, coastal aquaculture, Gerupuk Bay, West Nusa Tenggara

\section{PENDAHULUAN}

Dalam setiap pemilihan lokasi, pengelolaan, dan desain teknis untuk suatu kawasan budidaya, karakteristik fisik pantai seperti topografi dan pasang surut (pasut) merupakan informasi penting, dan merupakan variabel utama yang harus dipertimbangkan. Untuk kawasan pantai, karakteristik topografi berkaitan erat dengan karakteristik pasut, karena karakteristik pasut (tipe dan tunggang pasut) dapat mengubah bentuk dan luasan pantai secara fisik, begitu pula proses sedimentasi yang terjadi akibat pasut air laut. Hasil penelitian terdahulu juga menunjukkan bahwa informasi topografi dan pasut berkaitan erat dengan berbagai aktivitas perencanaan dan pengelolaan perikanan budidaya yang berbasis lahan. Untuk lokasi pertambakan Afrianto \& Liviawaty (1991) dan Poernomo (1992) menyarankan agar lokasi pertambakan sebaiknya dipilih pada tempat yang mempunyai elevasi antara 0,5-2,5 $\mathrm{m}$ di atas permukaan laut rata-rata agar memudahkan pengelolaan air, sehingga tambak cukup mendapatkan air dan dapat dikeringkan pada saat pasang harian. Bose et al. (1991) secara spesifik menjelaskan bahwa elevasi dasar tambak yang ideal adalah apabila dasar tambak dapat dikeringkan kapan saja dan dapat diisi air secara gravitasi selama lima hari dari setiap siklus pasut. Walaupun pada tambak intensif dan super-intensif justru lebih ideal pada lahan yang tidak terjangkau pasut untuk kemudahan dalam pembersihan dasar tambak, namun demikian karateristik topografi dan pasut tetap perlu diperhatikan untuk mengetahui lokasi pengambilan (pemompaan) air bersih sehingga tetap ekonomis, dan pada perairan tersebut terdapat volume yang memadai baik untuk proses pergantian air maupun untuk kebutuhan pengelolaan limbah budidaya.

Untuk mendukung peningkatan produksi perikanan nasional dan mewujudkan salah satu misi Dinas Kelautan dan Perikanan (DKP) Lombok Tengah dalam "meningkatkan kesejahteraan masyarakat melalui pemanfaatan dan pengelolaan sumberdaya kelautan dan perikanan secara optimal, terpadu dan berkelanjutan", Teluk Gerupuk dan Teluk Bumbang telah ditetapkan sebagai salah satu kawasan minapolitan rumput laut (Anonim, 2013). Data dari profil DKP Lombok Tengah menunjukkan potensi budidaya laut di Lombok Tengah sebesar 3.455 ha dengan tingkat pemanfaatan lahan hanya sekitar 646,6 ha (budidaya laut sebesar 579,6 ha; dan lobster, serta kerapu sebesar 67 ha), dan total produksi mencapai 44.571,1 ton (Anonim, 2013). Dari total pemanfaatan lahan tersebut sekitar $67,8 \%(438,6$ ha) berlokasi di Teluk Gerupuk yang dimanfaatkan untuk budidaya rumput laut (Anonim, 2013). Dengan demikian Teluk Gerupuk merupakan wilayah pengembangan rumput laut dan pemanfaatan lahan untuk budidaya laut terbesar di Kabupaten Lombok Tengah. Namun demikian, perkembangan terakhir menunjukkan adanya penurunan alih fungsi sebagian besar lahan budidaya rumput laut menjadi pemanfaatan untuk sektor perikanan lainnya seperti untuk penangkapan benih lobster dan pembesaran ikan kerapu; serta untuk kegiatan wisata bahari (surfing). Di sisi lain, potensi pengembangan budidaya air payau (tambak udang dan bandeng) dianggap tidak ada sehingga tidak terdata, padahal dari aspek pengembangan wilayah perikanan pantai Teluk Gerupuk merupakan bagian dari Wilayah Pengembangan dan Pengelolaan (WP) II dengan komoditas utama rumput laut, lobster, udang, usaha garam rakyat, dan penangkapan ikan. Hal lain juga disebabkan karena kemungkinan kontribusi produksi yang kecil dan potensi kesesuaian lahan yang dianggap kurang mendukung. Menurunnya produksi unggulan rumput laut yang diikuti dengan munculnya unit usaha baru, memerlukan kajian yang mendalam mengenai tata ruang yang didasarkan dari aspek kesesuaian lahan. Aspek fisik yang paling mendasar untuk evaluasi kesesuaian perairan teluk untuk berbagai penggunaan lahan meliputi topografi dan hidrologi perairan.

Teluk Gerupuk dan Teluk Bumbang yang bermuara pada mulut teluk yang sama memiliki karakteristik topografi dan pola hidrologi pantai yang unik sehingga mendukung variasi penggunaan lahan. Untuk memahami lebih dalam mengenai faktor pendukung dan pembatas fisik lahan atau perairan di wilayah teluk tersebut, telah dilakukan penelitian yang bertujuan untuk mengetahui karakteristik fisik pantai meliputi aspek hidrologi dan topografi di kedua teluk tersebut kaitannya dengan tingkat kesesuaian dan daya dukung lahan untuk pengembangan perikanan budidaya pesisir yang meliputi budidaya tambak dan budidaya laut. Pada penelitian ini karakteristik hidrologi pantai secara khusus diwakili oleh variabel pasut sedangkan topografi pantai memanfaatkan kombinasi variabel kedalaman perairan dan elevasi lahan di sekitar teluk. 


\section{BAHAN DAN METODE}

\section{Lokasi dan Waktu Penelitian}

Penelitian dilakukan dari tanggal 3-19 Maret 2014 yang berlokasi di Teluk Gerupuk dan Teluk Bumbang Kecamatan Pujut Kabupaten Lombok Tengah Provinsi Nusa Tenggara Barat (NTB). Secara geografis wilayah kedua teluk tersebut terletak pada $116^{\circ} 20^{\prime} 3,7^{\prime \prime}-$ $116^{\circ} 22^{\prime} 53,3$ ” BT dan 856'1,3”-853'50,4” LS (Gambar 1). Kedua teluk tersebut bermuara pada mulut teluk yang sama dan menjadi satu-satunya tempat keluar masuknya air laut, sehingga dapat dianggap sebagai satu kawasan teluk. Di bagian pantai Teluk Gerupuk terdapat tambak air payau yang dikelola secara tradisional plus. Lokasi kedua teluk tersebut dapat ditempuh dari Praya, Ibukota Kabupaten Lombok Tengah, dengan jarak sekitar $40 \mathrm{~km}$ atau sekitar $33 \mathrm{~km}$ dari Bandara Internasional Lombok.

\section{Metode Pengumpulan dan Analisis Data}

Data yang dikumpulkan dalam penelitian ini meliputi: topografi (kedalaman perairan), kelandaian/ elevasi, dan pasut. Kegiatan pengukuran topografi seperti penempatan titik dan alur sampling dibantu dengan citra quickbird akuisisi 20 Agustus 2012. Pengukuran kedalaman atau batimetrik (pemeruman) perairan teluk dilakukan dengan menggunakan Garmin GPSMAP $178 C$ Sounder. Teknik penentuan lajur perum ditentukan berdasarkan metode lajur perum lurus menyebar (konvergen/divergen) (Mulyono et al., 1985). Posisi rata-rata transducer echosounder pada saat pengukuran kedalaman diatur secara konsisten pada kedalaman 0,4 m untuk menghindari noise dari gerakan permukaan laut akibat ombak dan gerakan kapal, dan posisi ini juga diperhitungkan sebagai faktor koreksi pada saat perhitungan kedalaman perairan yang sebenarnya di samping koreksi dari data pasut. Kecepatan rata-rata kapal 15 km/jam juga diatur sehingga tidak memengaruhi keakuratan pembacaan echosounder.

Pengukuran kelandaian dan elevasi pantai dilakukan mengikuti metode sipat memanjang dengan menggunakan teodolit tipe Nikon ${ }^{\circledR}$ Digital Theodolite NE-102 dan Kompas geologi (Purwoharjo, 1986). Dari hasil pengukuran ini ditentukan kemiringan dan ketinggian relatif wilayah pantai terhadap salah satu bidang referensi pasut seperti muka laut rata-rata (MLR). Karena pengukuran elevasi hanya sebatas wilayah pantai maka profil topografi wilayah di sekitar teluk didekati dengan memanfaatkan data elevasi digital (DEM) dari global digital elevation model (GDEM) Aster (format data geotiff) dengan resolusi spasial 30 m (Sumber data: JSS, 2011).

Pengamatan pasut dilakukan selama 15 piantan (sekitar 15 hari) dengan interval satu jam dan dimulai pada pukul 00.00 menggunakan palem atau rambu pengamat pasut yang dipasang di dermaga depan Instalasi Balai Budidaya Laut Lombok di Dusun Gerupuk Desa Sengkol. Data pasut tersebut dianalisis dengan metode least square untuk mendapatkan konstanta (komponen) harmonik pasut (Bose et al., 1991). Dari konstanta harmonik pasut tersebut selanjutnya dihitung berbagai datum referensi pasut dan juga tipe

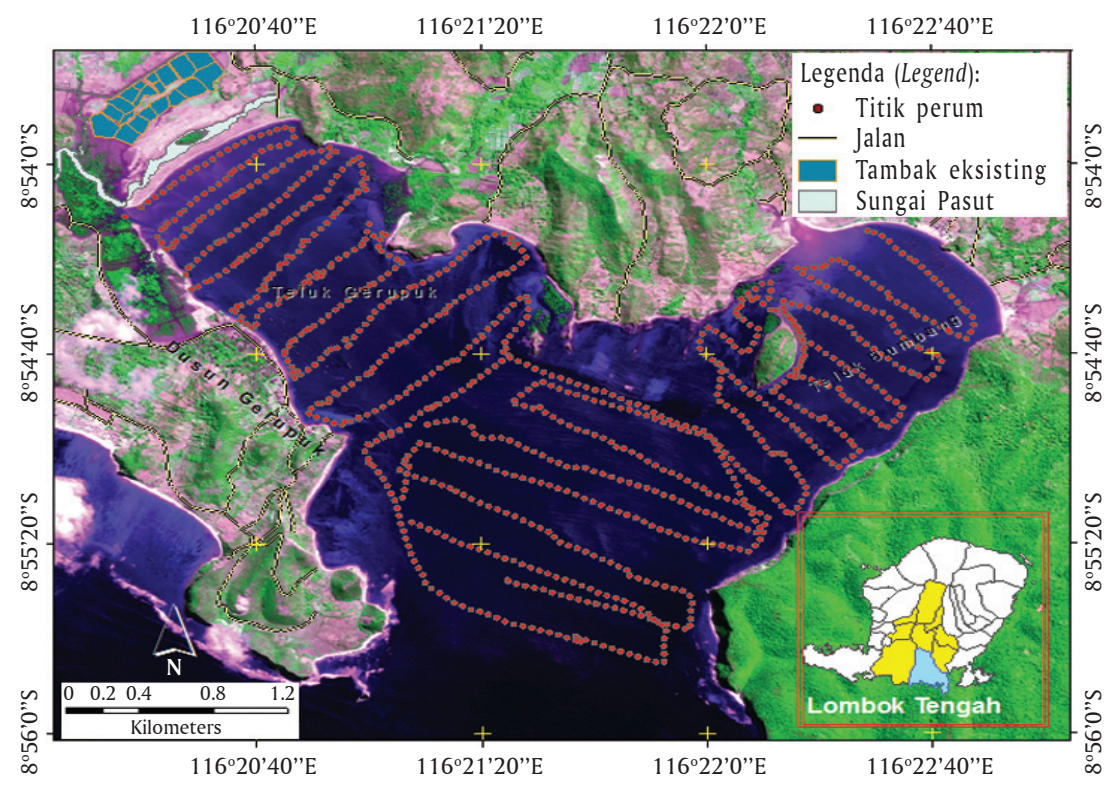

Gambar 1. Lokasi penelitian dan posisi titik perum (batimetri) di Teluk Gerupuk dan Teluk Bumbang, Lombok Tengah

Figure 1. The study area and the distribution of depth sounding points in Gerupuk and Bumbang Bays, Central Lombok 
pasut (berdasarkan tidal form factor, F) untuk perairan teluk tersebut menggunakan persamaan Masselink \& Hugest (2003):

$$
\mathrm{F}=\frac{\mathrm{K} 1+\mathrm{O} 1}{\mathrm{M} 2+\mathrm{S} 2}
$$

di mana:

$\mathrm{F} \quad=$ Bilangan Formzhal (Tidal form factor or Formzhal number)

$\mathrm{K} 1$ = Amplitudo unsur pasut tunggal yang disebabkan oleh gaya tarik matahari (Amplitude of luni-solar diurnal component)

01 = Amplitudo unsur pasut tunggal yang disebabkan oleh gaya tarik bulan (Amplitude of principal lunar diurnal component)

M2 = Amplitudo unsur pasut ganda utama yang disebabkan oleh gaya tarik bulan (Amplitude of principal lunar semi-diurnal component)

S2 = Amplitudo unsur pasut ganda utama yang disebabkan oleh gaya tarik matahari (Amplitude of principal solar semi-diurnal component)

Berdasarkan nilai $\mathrm{F}$ ini maka pasut bertipe: A) pasut harian ganda (semi-diurnal) jika F 70,25 ; B) pasut campuran (ganda dominan) jika 0,25 < F 7 1,5; C) pasut campuran (tunggal dominan) jika 1,5 < F 7 3; dan D) pasut harian tunggal (diurnal) F 8 3. Data pasut termasuk datum referensi pasut tersebut juga digunakan sebagai bidang referensi atau pengoreksi hasil pengukuran elevasi lahan dan batimetri. Selanjutnya hasil kombinasi antara data elevasi lahan dan batimetri yang terkoreksi dengan salah satu referensi permukaan pasut dianalisis untuk membuat peta topografi pantai dan peta batimetri, serta zonasi pasut di sepanjang pantai yang mengelilingi teluk.

Dengan memanfaatkan data yang sama pada saat pembuatan peta batimetri dan peta topografi, dihitung volume air teluk, dan volume prisma pasut (tidal prism). Selanjutnya berdasarkan nilai volume teluk dan volume prisma pasut tersebut, diestimasi curahan atau bilasan pasang (tidal flushing) dengan memanfaatkan modifikasi one-dimensional box model yang dikembangkan oleh Moore (2000) melalui penambahan komponen fractional rate of exchange $(\alpha)$. Nilai $\alpha$ tersebut mengasumsikan bahwa hampir tidak mungkin pada suatu perairan seperti teluk akan terjadi pembilasan sempurna (100\%) untuk satu kali siklus pasut (tidal cycle). Model bilasan pasut ini merupakan pendekatan sederhana untuk mengestimasi kemampuan perairan dalam mengencerkan bahan pencemar seperti logam berat hingga konsentrasi tertentu. Pada evaluasi ini digunakan kisaran nilai $\alpha$ dari 100 hingga 25\% dan nilai konsentrasi awal $\left(C_{0}\right)$ ditetapkan sebesar 10 , sementara konsentrasi akhir $\left(C_{n}\right)$ sebesar 5 . Perhitungan jumlah siklus pasut menggunakan persamaan Moore (2000):

$$
N=\frac{\ln \left(C_{o} / C_{n}\right)}{\ln \left(1+\left[\left(V_{P} / V_{L}\right) \times \alpha\right]\right)}
$$

di mana:

$\mathrm{N}=$ Jumlah siklus pasut (Number of tidal cycles)

$\mathrm{C}_{\mathrm{o}}=$ Konsentrasi awal (Initial concentration) (Dimensionless)

$\mathrm{C}_{\mathrm{n}}=$ Konsentrasi akhir (Final concentration) (Dimensionless)

$\mathrm{V}_{\mathrm{p}}=$ Volume prisma pasut (Volume of the tidal prism) $\left(\mathrm{m}^{3}\right)$

$\mathrm{V}_{\mathrm{L}}=$ Volume teluk saat MLLW (Volume of the bay at MLLW) $\left(\mathrm{m}^{3}\right)$

$\alpha=$ Derajat laju pergantian (Fractional rate of exchange)

Data topografi (elevasi pantai dan batimetri) hasil survai lapang dan DEM diolah dengan menggunakan perangkat lunak excel, surfer, ArcGIS 10.0, dan MapInfo 9.0. Hasil analisis data topografi dan pasut tersebut dipresentasikan dalam bentuk tabel, peta, dan grafik dan diinterpretasi berdasarkan relevansinya untuk pemanfaatan dan pengembangan perikanan budidaya pesisir.

\section{HASIL DAN BAHASAN}

\section{Kondisi Pasang Surut}

Amplitudo untuk setiap konstanta atau komponen harmonis pasut hasil analisis berdasarkan metode least square untuk data 15 piantan pengukuran pasut ditampilkan pada Tabel 1. Hasil pengukuran pasut selama 15 piantan di Teluk Gerupuk disajikan pada Gambar 2.

Berdasarkan nilai konstanta harmonik pasut tersebut maka dapat disimpulkan bahwa tipe pasut untuk Teluk Gerupuk adalah tipe 'campuran condong ke semi-diurnal' (mixed-type, semi-diurnal dominance) dengan nilai $F=0,29$. Dengan tipe pasut demikian, pergantian air di teluk umumnya dapat terjadi dua kali dalam 24 jam. Ketinggian pasut rata-rata (MSL) di lokasi pengukuran pasut (Dermaga, posisi 8`54'43,9” LS dan $116^{\circ} 20^{\prime} 46,31$ ” BT) adalah $1,75 \mathrm{~m}$. Tunggang pasut (tidal range) terbesar selama 15 piantan didapatkan dari hasil pengukuran langsung sebesar 2,85 m (hasil prediksi $=2,97 \mathrm{~m}$ ) yang dapat terjadi baik saat bulan purnama maupun bulan mati (spring tide) sedangkan tunggang pasut terendah sebesar $0,36 \mathrm{~m}$ terjadi pada saat fase bulan $1 / 4$ dan $3 / 4$ atau bulan perbani (neap tide). Didasarkan pada referensi muka laut rata-rata lokal tersebut, diketahui pasut tertinggi yang diukur (Highest Measured Tide) sebesar +1,50 m dan didapatkan ketinggian Mean Higher High Water (MHHW) meter dan Mean High Water (MHW) masing-masing sebesar $+1,24$ dan $+0,96$ dari MSL. Sedangkan untuk Mean Low Lower Water dan Mean Lower Low Water (MLLW) diprediksikan berada masing-masing sebesar -96 dan $-1,24$ dari MSL. Hasil analisis konstanta astronomis utama pasut tersebut juga mengindikasikan bahwa di samping pengaruh utama faktor astronomis (posisi 
Tabel 1. Konstanta harmonik pasut utama di Teluk Gerupuk, Lombok Tengah Table 1. Major tide harmonic constituents in Gerupuk Bay, Central Lombok

\begin{tabular}{ccc}
\hline Konstanta utama (Constanta) & $\begin{array}{c}\text { Amplitudo } \\
\text { Amplitude } \mathbf{( c m )}\end{array}$ & $\begin{array}{c}\text { Periode } \\
\text { (Period) }\end{array}$ \\
\hline Tengah harian (Semidiurnal) & & \\
M2, Principal lunar & 76 & 12.42 \\
S2, Principal solar & 21 & 12 \\
N2, Larger lunar elliptic & 11 & 12.66 \\
K2, Luni-solar semi-diurnal & 41 & 11.97 \\
\hline Harian (Diurnal) & & \\
K1, Luni-solar diurnal & 18 & 23.93 \\
O1, Principal lunar diurnal & 10 & 25.82 \\
P1, Principal solar diurnal & 19 & 24.07 \\
\hline
\end{tabular}

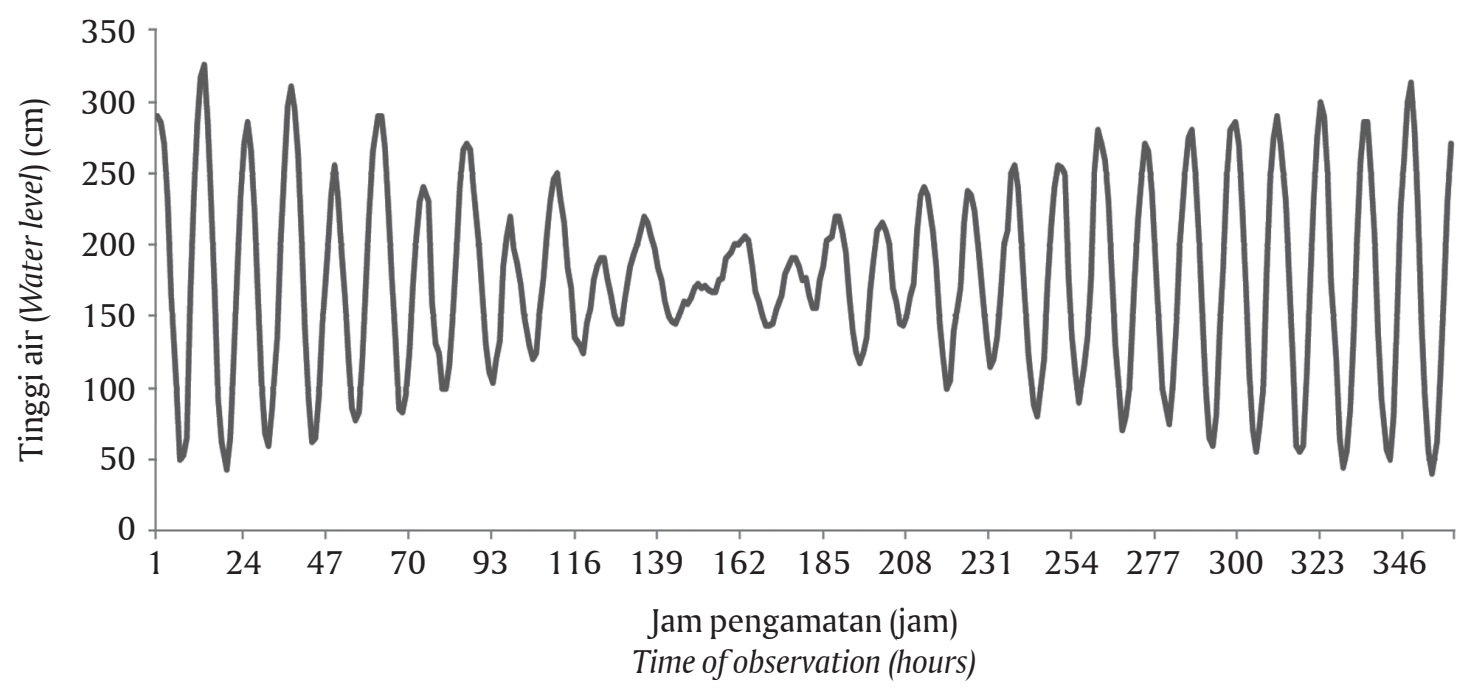

Gambar 2. Hasil pengukuran pasut selama 15 piantan (5-19 Maret 2014) di Teluk Gerupuk

Figure 2. Tide of Gerupuk Bay recorded from 5 to 19 March 2014

bulan dan matahari) terdapat pengaruh lokal antara lain topografi teluk (bentuk teluk, arah mulut teluk yang mengarah ke Samudera Hindia dan kedalaman perairan) terhadap nilai amplitudo pasut. Menurut Poernomo (1992), nilai tunggang pasut yang mendekati $3 \mathrm{~m}$ masih tergolong ideal untuk pengembangan dan pengelolaan tambak udang meskipun cukup membutuhkan dukungan pematang yang kokoh yang bergantung pada kualitas tanah dan teknik konstruksi untuk menahan tekanan air pada saat pasang dan mempertahankan ketinggian air dalam petakan tambak pada saat surut. Tipe pasut juga tergolong ideal untuk mendukung pergantian air selama kegiatan budidaya dan pembilasan limbah budidaya terutama untuk tambak udang intensif dan superintensif.

Untuk elevasi tambak tradisional plus hingga semiintensif ketinggian dasar tambak sebaiknya terletak di antara rataan pasang tinggi (MHHW) dan rataan pa- sang rendah (MLLW) atau dengan kata lain berada di sekitar ketinggian mean sea level (MSL). Dalam sistem zonasi pasut, kawasan yang berada pada ketinggian ini lebih dikenal dengan istilah kawasan intertidal. Karena elevasi kawasan intertidal masih lebih rendah dari air pasang tinggi terendah atau rataan pasang tinggi, maka air dapat dengan mudah dialirkan ke tambak secara gravitasi pada saat pasang tinggi tanpa penggunaan pompa (Poernomo, 1992). Ketinggian dasar tambak tersebut disarankan berdasarkan kedalaman air yang dikehendaki dan pertimbangan ekonomis konstruksi. Sedangkan untuk tambak superintensif, karena pasokan air dilakukan sepenuhnya mengandalkan pompa maka disarankan agar posisi dasar tambak minimum setinggi MHHW atau kawasan supratidal untuk memudahkan proses pengeringan dan pembersihan dasar tambak. Kawasan supratidal merupakan areal atau daerah kawasan pantai di atas jangkauan pasut dan ada kalanya daerah yang terjang- 
kau air laut hanya pada saat pasang tinggi tertinggi sekali setiap tahunnya juga dimasukkan dalam zona ini (Poernomo, 1992).

Pemanfaatan lahan intertidal di sekitar teluk saat ini masih terbatas untuk budidaya udang vaname dan udang windu sistem tradisional plus. Namun demikian seiring dengan meningkatnya kebutuhan lokal dan dorongan nasional untuk peningkatan produksi budidaya, maka hampir dipastikan akan terjadinya perubahan sistem budidaya ke arah yang lebih intensif. Perubahan sistem budidaya ke arah yang lebih intensif akan diikuti dengan peningkatan input produksi seperti: pakan, pupuk, dan pestisida yang tinggi, sekaligus menyebabkan terjadinya peningkatan beban limbah bagi perairan teluk. Walaupun karakteristik pasut secara alami dapat mengantisipasi beban limbah melalui pergantian air, akan tetapi menurut Hari et al. (2006), pada sistem budidaya tradisional saja pergantian air hanya mampu membilas $2,7 \%$ total nitrogen yang dihasilkan selama budidaya dan selebihnya $21 \%$ dan $67 \%-71 \%$ masing-masing akan tertinggal dalam tubuh udang dan terendapkan dalam sedimen. Limbah yang terlarut dalam air pada saat kegiatan budidaya dan sebagian lagi yang berasal dari sedimen saat persiapan lahan tambak akan berakhir di perairan laut sehingga akan dibutuhkan kuantitas air penerima limbah yang cukup untuk menetralisir limbah agar perairan tidak tercemar. Menurut Racocy \& Alison (1981) dalam Widigdo \& Pariwono (2003), agar perairan tidak tercemar maka dibutuhkan kuantitas air laut penerima limbah minimal 100 kali dari kuantitas limbah yang dibuang.

\section{Kondisi Topografi Pantai dan Dasar Perairan}

Peta kelandaian pantai dan batimetrik disajikan pada Gambar 3. Dari total 1.286 titik perum yang tersebar secara merata di lokasi penelitian dengan luas sekitar 940 ha $\left(9,40 \mathrm{~km}^{2}\right)$ pada saat pasut rata-rata, didapatkan kedalaman maksimum teluk sebesar $17 \mathrm{~m}$ dengan kedalaman rata-rata 4,17 $\pm 0,12 \mathrm{~m}$. Dengan kondisi kedalaman perairan tersebut, merupakan faktor pembatas pemanfaatan lahan untuk pengembangan budidaya laut dengan keramba jaring apung (KJA), karena kedalaman perairan optimal untuk operasional KJA berkisar antara 8-25 m (Tarunamulia et al., 2009). Wilayah Teluk Gerupuk dan Teluk Bumbang dengan kedalaman perairan sekitar 3-6 m yang awalnya dimanfaatkan untuk budidaya rumput laut, kini utamanya dimanfaatkan untuk penangkapan benih lobster alam sistem rakit. Sampai pada bulan Maret 2014, jumlah rakit yang ada sudah mencapai sekitar 400 rakit. Sedangkan budidaya rumput laut hanya terkonsentrasi pada bagian teluk terdalam yang terletak di sekitar mulut teluk.
Kondisi topografi di sekitar teluk umumnya berbukit dengan ketinggian rata-rata $33 \mathrm{~m}$ dari rata-rata muka laut dan dicirikan dengan wilayah pantai yang sempit (hanya selebar 1 hingga 1,5 km dari garis pantai). Areal pantai yang paling landai $(<2 \%)$ berada pada sisi Barat Laut Teluk Gerupuk dengan luas zona intertidal sebesar 120 ha. Wilayah pantai yang landai pada bagian sisi Barat Laut Teluk Gerupuk saat ini sedang digunakan dan dikembangkan untuk budidaya tambak udang dan bandeng sistem tradisional plus, serta untuk perkebunan. Sedangkan wilayah pemukiman (Dusun Gerupuk) terkonsentrasi pada bagian sisi sebelah Barat teluk. Kawasan perbukitan sebagian besar dimanfaatkan sebagai wilayah konservasi (sisi Timur wilayah teluk) dan bangunan villa/hotel untuk wisata laut dan pantai. Pada saat musim hujan, meskipun tidak terdapat sungai hidup (air tawar) yang bermuara, teluk akan menjadi satu-satunya wadah penampungan (sink) dari berbagai run-off permukaan yang berasal dari wilayah perbukitan/daratan sekeliling di sisi teluk.

Jika terjadi konversi lahan perbukitan (daerah kemiringan) dan catchment area di sekeliling teluk, kemungkinan akan merubah karakteristik kimia fisika seperti suhu, salinitas, dan kekeruhan air laut di teluk tersebut, yang pada akhirnya akan memiliki dampak pada status kesesuaian dan keberlanjutan kegiatan budidaya rumput laut, Kappaphycus alvarezii yang terbukti rentan terhadap sedimentasi (Parenrengi et al., 2011). Menurunnya produksi dari usaha budidaya rumput laut saat ini jika dibandingkan dengan beberapa periode sebelumnya boleh jadi berkaitan dengan terjadinya konversi atau alih-fungsi lahan tersebut atau kombinasi dengan faktor lingkungan lainnya. Hasil kajian yang dilakukan oleh Radiarta et al. (2013) menunjukkan bahwa perubahan kondisi lingkungan perairan dan iklim yang terjadi belakangan ini juga merupakan penyebab utama penurunan hasil rumput laut di lokasi penelitian. Seiring dengan penurunan produksi rumput laut dan meningkatnya aktivitas pengumpulan lobster menyebabkan banyak pembudidaya rumput laut yang beralih menjadi penangkap lobster.

\section{Estimasi Volume Air Tersedia dan Tidal Flushing}

Kuantitas air laut penerima limbah harus cukup tersedia untuk menerima beban limbah agar perairan tidak tercemar dan masih dalam status yang layak untuk peruntukan lain termasuk untuk budidaya laut. Volume teluk untuk berbagai kondisi tinggi pasut disajikan pada Tabel 2. Berdasarkan nilai volume teluk pada saat muka laut rata-rata dan kriteria minimum 100 kali kuantitas air penerima limbah maka perairan teluk tersebut diprediksi hanya mampu menganti- 

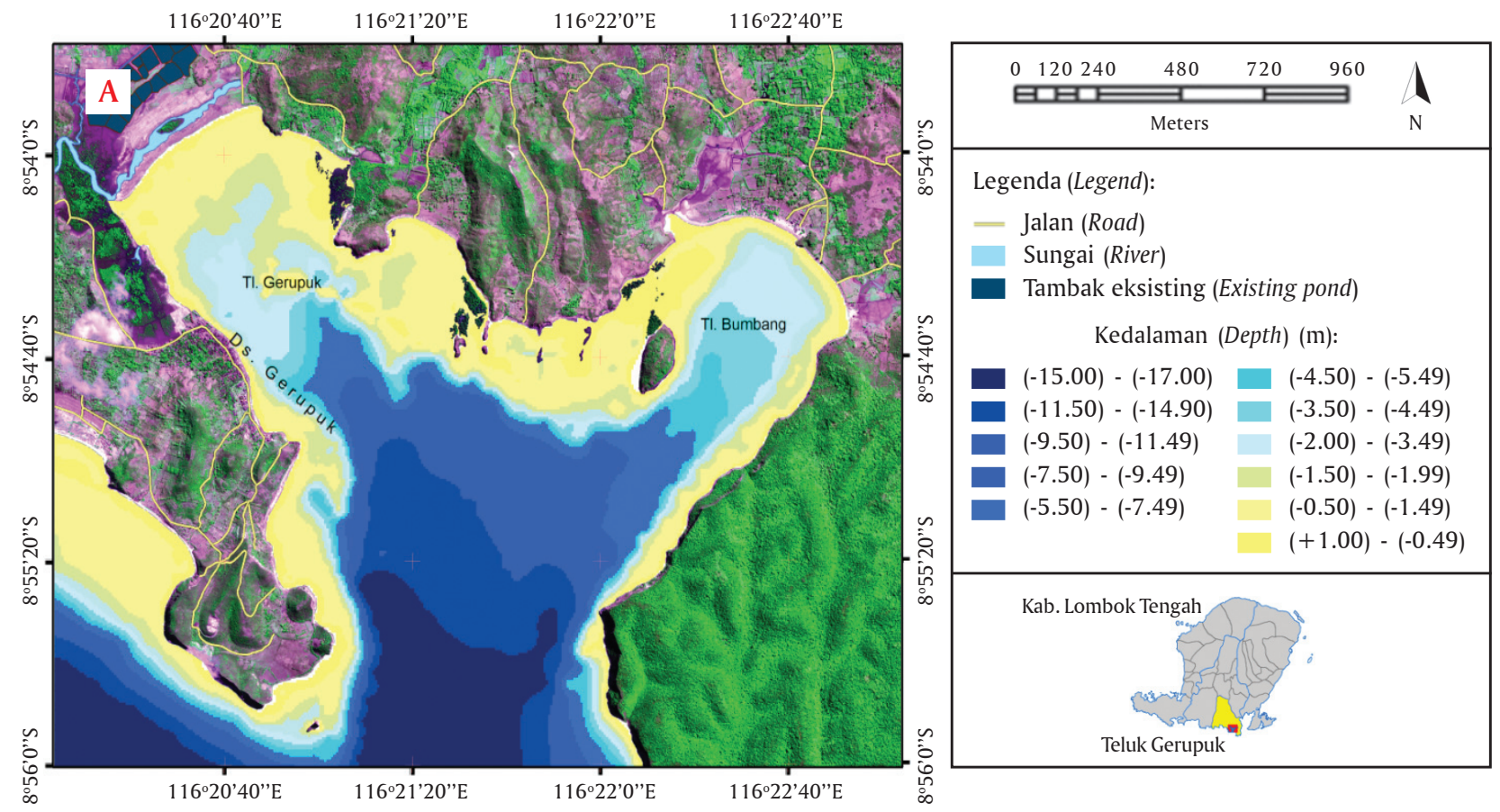

B

Tambak eksisting (Existing pond)
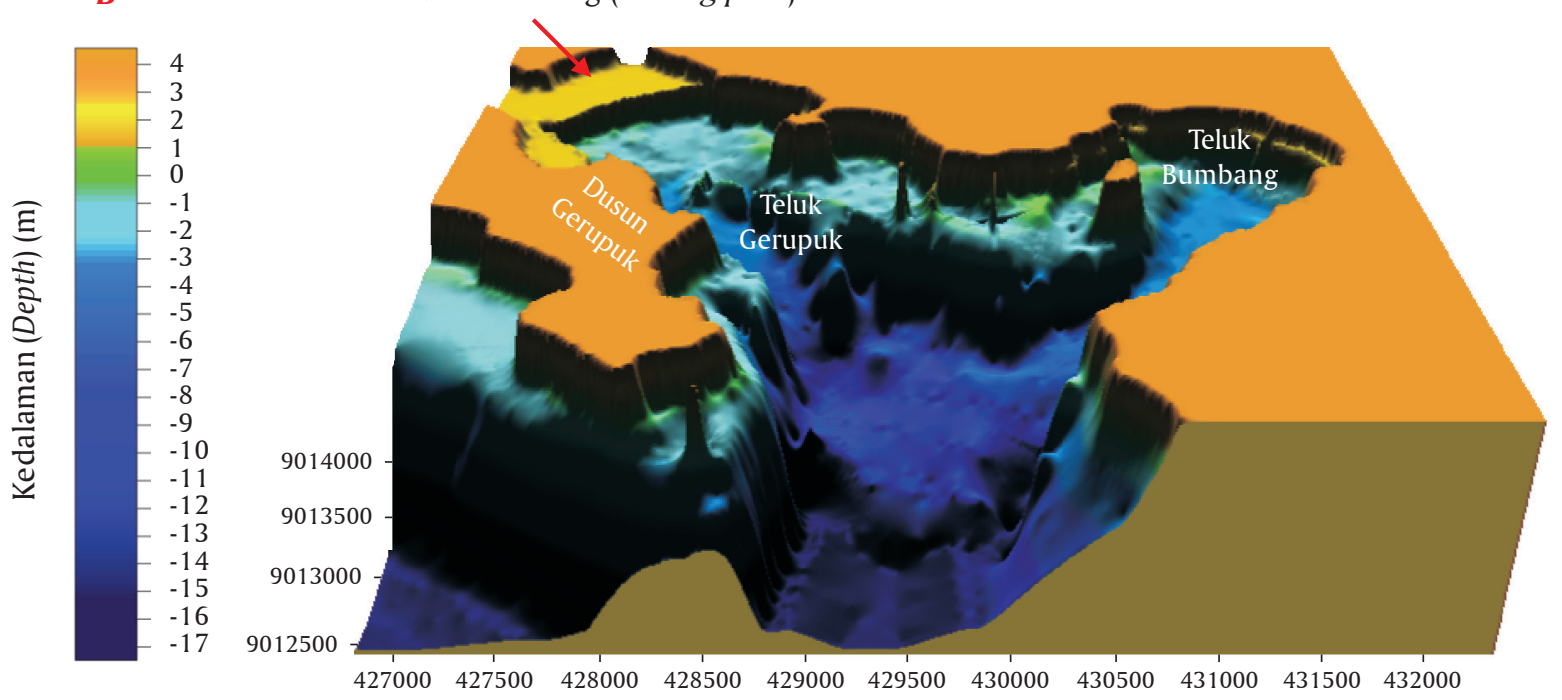

Gambar 3. Topografi dasar perairan Teluk Gerupuk dan Teluk Bumbang, Lombok Tengah: Peta kedalaman (A) dan kenampakan 3-dimensi (B)

Figure 3. Bottom topographic of Gerupuk and Bumbang Bays, Central Lombok: Bathymetric map (A) and 3D-view (B)

sipasi beban limbah sebesar $\pm 520.440 \mathrm{~m}^{3}$ per siklus pasang. Namun demikian variabel kuantitas air perairan hanya merupakan salah satu prasyarat umum dan masih bergantung pada berbagai peubah lain seperti siklus pasut dan tingkat efisien pengenceran yang dapat berbeda sesuai dengan karakteristik lokal topografi dan hidrologi perairan, serta sifat atau karakteristik bahan pencemar yang masuk ke perairan. Berdasarkan nilai volume teluk setiap datum referensi pasut, diperoleh volume prisma pasut $(\mathrm{Vp})=$ 24306119,5 $\mathrm{m}^{3}$ pada saat tunggang pasut maksimum dan $\mathrm{Vp}=10365042,1$ saat rataan tunggang pasut.
Hasil estimasi tidal flushing untuk Teluk Gerupuk dan Bumbang (Tabel 3), secara umum menjelaskan jumlah siklus pasang yang diperlukan untuk mencapai pengurangan atau pengenceran konsentrasi hingga 50\%; berkisar antara 2 hingga 23 siklus pasut atau 1 hingga 12 hari. Untuk tingkat efisiensi yang sama tetapi tidal range (tunggang pasut) yang berbeda maka didapatkan perbedaan dua kali nilai siklus pasang dan surut $(\mathrm{N})$, hal ini menunjukkan peranan utama dari tunggang pasut dalam proses pengenceran limbah pencemar. Karena tipe pasut untuk wilayah teluk tersebut adalah campuran yang condong ke pasut ganda, 
Tabel 2. Volume dan luas permukaan teluk pada setiap datum referensi permukaan pasut di Teluk Gerupuk dan Teluk Bumbang, Lombok Tengah

Table 2. Volume and surface areas of the bay calculated from different tide reference datum in Gerupuk and Bumbang Bays, Central Lombok

\begin{tabular}{lcc}
\hline \multicolumn{1}{c}{$\begin{array}{c}\text { Datum referensi permukaan pasut } \\
\text { Tide reference datum }\end{array}$} & Volume $\left(\mathbf{m}^{3}\right)$ & $\begin{array}{c}\text { Luas permukaan } \\
\text { Surface areas }\left(\mathbf{m}^{2}\right)\end{array}$ \\
\hline Pasang tertinggi yang diukur (Highest measured tide) (HMT) & 65985069.15 & 9464318.65 \\
Rataan pasang tinggi (Mean higher high water) (MHHW) & 63528317.43 & 9404639.5 \\
Muka laut rata-rata (Mean sea level) (MSL) & 52043991.71 & 9052973.76 \\
Rataan pasang rendah (Mean lower low water) (MLLW) & 41678949.6 & 7153048.18 \\
\hline
\end{tabular}

Tabel 3. Jumlah siklus pasut $(\mathrm{N})$ yang dibutuhkan untuk merubah hingga $50 \%$ terhadap suatu nilai konsentrasi $(C)$

Table 3. Number of tidal cycles (N) required affecting a 50\% change in concentration (C)

\begin{tabular}{|c|c|c|c|c|c|c|c|}
\hline Co & $\mathrm{Cn}$ & $V_{P}\left(m^{3}\right)$ & $V_{L}\left(m^{3}\right)$ & $\alpha$ & $\mathbf{N}$ & $\begin{array}{l}\mathrm{T} 1 / 2 \\
\text { hari }(\text { day })\end{array}$ & Asumsi (Assumption) \\
\hline 10 & 5 & 24306119.5 & 41678949.6 & 1.0 & 1.5 & 0.75 & $\begin{array}{l}\text { Tunggang pasut maksimum \& efisiensi pergantian } 100 \% \\
\text { Maximal tidal range \& } 100 \% \text { efficiency of exchange }\end{array}$ \\
\hline 10 & 5 & 10365042.1 & 41678949.6 & 1.0 & 3.1 & 1.56 & $\begin{array}{l}\text { Rataan tunggang pasut \& efisiensi pergantian } 100 \% \\
\text { Mean tidal range \& } 100 \% \text { efficiency of exchange }\end{array}$ \\
\hline 10 & 5 & 24306119.5 & 41678949.6 & 0.5 & 2.7 & 1.35 & $\begin{array}{l}\text { Tunggang pasut maksimum \& efisiensi pergantian } 50 \% \\
\text { Maximal tidal range \& } 50 \% \text { efficiency of exchange }\end{array}$ \\
\hline 10 & 5 & 10365042.1 & 41678949.6 & 0.5 & 5.9 & 2.96 & $\begin{array}{l}\text { Rataan tunggang pasut \& efisiensi pergantian } 50 \% \\
\text { Mean tidal range \& } 50 \% \text { efficiency of exchange }\end{array}$ \\
\hline 10 & 5 & 24306119.5 & 41678949.6 & 0.25 & 5.1 & 2.55 & $\begin{array}{l}\text { Tunggang pasut maksimum \& efisiensi pergantian } 25 \% \\
\text { Maximal tidal range \& } 25 \% \text { efficiency of exchange }\end{array}$ \\
\hline 10 & 5 & 10365042.1 & 41678949.6 & 0.25 & 11.5 & 5.75 & $\begin{array}{l}\text { Rataan tunggang pasut \& efisiensi pergantian } 25 \% \\
\text { Mean tidal range \& } 25 \% \text { efficiency of exchange }\end{array}$ \\
\hline 10 & 5 & 24306119.5 & 41678949.6 & 0.125 & 9.9 & 4.93 & $\begin{array}{l}\text { Tunggang pasut maksimum \& efisiensi pergantian } 12,5 \% \\
\text { Maximal tidal range \& } 12.5 \% \text { efficiency of exchange }\end{array}$ \\
\hline 10 & 5 & 10365042.1 & 41678949.6 & 0.125 & 22.6 & 11.32 & $\begin{array}{l}\text { Rataan tunggang pasut \& efisiensi pergantian } 12,5 \% \\
\text { Mean tidal range \& } 12.5 \% \text { efficiency of exchange }\end{array}$ \\
\hline
\end{tabular}

maka siklus pasang dan surut atau pembilasan dapat terjadi dua kali dalam 24 jam. Hasil studi Walton (1983) dalam Moore (2000) membuktikan pendekatan estimasi dengan one-dimension box model ini akan menghasilkan estimasi awal ("back-of the envelope calculation") yang cukup logis jika semua asumsi dipertimbangkan, namun demikian dengan penambahan nilai efisiensi pergantian $(\alpha)$ kemungkinan hasil estimasinya akan lebih rendah dari waktu (hari) dan jumlah siklus pasut yang dibutuhkan. Model ini juga belum mempertimbangkan adanya variasi spasial dari suatu "pencemar" setelah keluar dari sumbernya. Hasil kajian dari Bui et al. (2012) menunjukkan bahwa terdapat variasi spasial konsentrasi bahan pencemar dengan dampak yang lebih besar terutama di sekitar saluran pembuangan dari suatu hamparan budidaya yang ak- tif dengan radius variasi yang berkurang pada jarak 1-2 km dari sumber buangan limbah. Lebih lanjut dijelaskan, perubahan kualitas air yang paling mencolok ditemukan terutama pada saat musim panas setelah panen awal. Dengan demikian analisa tidal flushing juga harus memperhatikan aspek variasi ruang dan waktu (spatio-temporal analysis) untuk menghasilkan model yang lebih mendekati kondisi sebenarnya.

Data kuantitas air yang tersedia untuk mendukung kegiatan budidaya laut sekaligus untuk mengantisipasi beban limbah yang akan ditimbulkan merupakan informasi penting untuk penilaian awal daya dukung lahan untuk budidaya perikanan pesisir secara fisik di lokasi penelitian. Pemanfaatan informasi kuantitas air yang tersedia secara alami tersebut telah dilakukan 
oleh Mustafa \& Tarunamulia (2009) untuk menentukan daya dukung lahan terhadap tambak ekstensif di Kecamatan Balusu Kabupaten Barru Provinsi Sulawesi Selatan yang didasarkan pada kapasitas alamiahnya untuk menampung limbah agar produktivitas tambak dapat meningkat dan berkelanjutan. Pada praktek pengelolaan wilayah pesisir yang benar, sumber limbah yang harus dipertimbangkan dan ditangani bukan hanya yang berasal dari kegiatan budidaya tetapi juga limbah dari aktivitas penggunaan lahan lain seperti: limbah rumah tangga, hotel atau dari kegiatan pertanian tanaman pangan di sekitar teluk.

\section{Perspektif Karakteristik Fisik Pantai Terhadap Pengembangan Perikanan Budidaya}

Meskipun karakteristik fisik pantai yang dibahas dalam penelitian ini hanya terbatas pada variabel spesifik antara lain: pasut, kedalaman perairan, dan elevasi lahan di wilayah teluk, namun setidaknya model karakteristik fisik pantai ini efektif dalam mengungkap dua isu penting sehubungan dengan prospek pengembangan perikanan budidaya di wilayah penelitian.

Hasil kajian karakteristik fisik pantai ini mampu menyarankan atau membatasi wilayah (luas dan lokasi) yang berpeluang untuk pengembangan perikanan budidaya. Di samping itu, kajian ini juga dapat menyarankan budidaya yang tepat untuk diaplikasikan sehubungan keberadaan faktor pembatas fisik. Seperti pada pembahasan sebelumnya bahwa karakteristik pantai terutama di sisi Barat Teluk Gerupuk dengan tunggang pasut yang mendekati $3 \mathrm{~m}$ secara teknis masih tergolong ideal untuk pengembangan berbagai sistem budidaya tambak (tradisional plus, semiintensif, intensif, dan super-intensif), namun masih harus ditopang dengan kualitas tanah penyusun pematang yang baik untuk pengelolaan air tambak. Akan tetapi untuk pengembangan tambak intensif dan super-intensif di sisi Barat teluk tersebut, topografi dasar perairan yang landai dengan kedalaman rata-rata hanya sekitar $4 \mathrm{~m}$ dan rentang pasut yang besar tersebut dapat menjadi faktor pembatas yang harus dicermati sehubungan dengan jauhnya jarak pengambilan air bersih. Demikian halnya dengan kriteria kedalaman dan topografi perairan menunjukkan terbatasnya lahan yang tersedia dan dapat dimanfaatkan untuk budidaya laut melalui sistem keramba jaring apung (KJA).

Hasil kajian karakteristik fisik pantai ini juga mampu menjelaskan status pengembangan perikanan budidaya bilamana terjadi pengembangan sektor lain termasuk sektor perikanan budidaya di wilayah teluk. Sebagai contoh, jika aktivitas konversi lahan perbukitan di sekitar wilayah teluk terus berlanjut, dapat di- pastikan akan berdampak pada status kesesuaian dan keberlanjutan kegiatan budidaya perikanan di wilayah tersebut. Contoh lainnya adalah meskipun pada dasarnya kedalaman perairan cukup memadai untuk kegiatan budidaya rumput laut, namun demikian masih banyak faktor pembatas lain yang harus diperhatikan termasuk pengaruh perubahan iklim dan musim tanam optimal, serta keberadaan aktivitas dari sektor lain yang juga memiliki nilai ekonomis penting seperti kegiatan pariwisata dan penangkapan benih lobster. Khususnya untuk wilayah Barat Teluk Gerupuk, sumber pasokan dan pembuangan air baik untuk tambak eksisting maupun untuk pengembangan dengan karakteristik topografi semuanya hanya mengandalkan wilayah teluk, sehingga perlu dipertimbangkan sistem penanganan limbah termasuk rencana umum tata ruang wilayah agar tidak mengganggu stabilitas ekologis dan tidak memicu konflik penggunaan lahan baik antar sistem budidaya maupun dengan sektor lain (pariwisata, pertanian/perkebunan, dan perikanan tangkap) yang pada akhirnya akan mengganggu keberlanjutan usaha budidaya. Kajian karakteristik fisik pantai dapat digunakan sebagai data dukung awal untuk melihat kemampuan alami perairan dalam menangani limbah yang masuk ke perairan.

Namun demikian, karakteristik fisik pantai sangat terbatas untuk menjelaskan fenomena spesifik yang terjadi karena kesalahan manajemen dan faktor perubahan iklim. Sebagai contoh, fenomena menurunnya produksi unggulan rumput laut yang merupakan komoditas primadona di wilayah penelitian yang diikuti dengan munculnya unit usaha baru dan seolaholah dapat menggantikan komoditas utama tersebut, memerlukan kajian yang mendalam terutama mengenai aspek keberlanjutan usaha dan tata ruang wilayah. Karena munculnya unit usaha budidaya yang baru bisa jadi justru merupakan pemicu menurunnya produksi budidaya lain yang terlebih dahulu dikembangkan di wilayah tersebut. Pengembangan kegiatan perikanan budidaya sudah seharusnya direncanakan secara mendalam dengan melibatkan lebih banyak variabel lain termasuk kajian sosial ekonomi sehingga kejadian yang sama tidak terjadi pada sektor unggulan lainnya.

\section{KESIMPULAN}

Berdasarkan hasil analisis, maka secara umum disimpulkan bahwa karakteristik variabel hidrologi dan topografi akan menjadi faktor pendukung sekaligus faktor pembatas bagi pengembangan perikanan budidaya pesisir di lokasi penelitian. Variabel turunan dari hasil kombinasi kedua variabel tersebut seperti ketersediaan air dan tidal flushing dapat dijadikan variabel utama untuk penentuan daya dukung lahan 
atau perairan. Keberadaan penggunaan lahan selain untuk kegiatan perikanan budidaya yang dapat memengaruhi kondisi kedua variabel lingkungan tersebut akan secara langsung maupun tidak langsung juga memengaruhi kondisi budidaya eksisting, serta potensi pengembangannya.

\section{UCAPAN TERIMA KASIH}

Penulis mengucapkan terima kasih kepada para teknisi Balai Penelitian dan Pengembangan Budidaya Air Payau (BPPBAP), Maros yang telah membantu kelancaran pelaksanaan kegiatan lapang. Terima kasih juga diucapkan kepada Bapak Dr. I Nyoman Radiarta, M.Sc., peneliti pada Pusat Penelitian dan Pengembangan Perikanan Budidaya (P4B) atas penyediaan citra quickbird untuk lokasi penelitian. Penelitian Sumberdaya Lahan dan Lingkungan Perikanan Budidaya Pesisir, BPPBAP, Maros ini dibiayai dari Proyek APBN tahun 2014.

\section{DAFTAR ACUAN}

Afrianto, E., \& Liviawaty, E. (1999). Teknik pembuatan tambak udang. Yogyakarta, $132 \mathrm{hlm}$.

Anonim. (2013). Profil Dinas Kelautan dan Perikanan Kabupaten Lombok Tengah Provinsi Nusa Tenggara Barat. Praya: Dinas Kelautan dan Perikanan Kabupaten Lombok Tengah, 26 hlm.

Bose, A.N., Ghosh, S.N., Yang, C.T., \& Mitra, A. (1991). Coastal aquaculture engineering. Edward Arnold. New York, 360 pp.

Bui, T.D., Luong-Van, J., \& Austin, C.M. (2012). Impacts of shrimp farm effluent on water quality in coastal areas of the world heritage-listed Ha Long Bay. American Journal of Environmental Sciences, 8(2), 104-116.

Hari, B., Kurup, B.M., Varghese, J.T., Schrama, J.W., \& Verdegem, M.C.J. (2006). The effect of carbohydrate addition on water quality and the nitrogen budget in extensive shrimp culture systems. Aquaculture, 252, 248-263.

JSS. (2011). Aster Global Digital Elevation Model (GD EM). Retrieved 12 March 2014, from Japan Space Systems, http://www.jspacesystems.or.jp/ersdac/ GDEM/E/4.html

Masselink, G., \& Huges, M.G. (2003). Introduction to coastal processes and geomorphology. Arnold. New York, 354 pp.
Moore, D.W. (2000). An evaluation of tidal flushing for shelter Island Yacht Basin using a simple tidal prism model. Retrieved from http://www. portofsandiego.org/bpc-policies/doc_view/3206study-an-evaluation-of-tidal-flushing-for-shelterisland-yacht-basin-2000.html

Mulyono, T., Sumartono, D., Priatna, K., Raharjo, P., \& Nadeak, D. (1985). Dasar-dasar teknik dan pelaksanaan survei batimetrik (Pemeruman). Kelompok Studi Kelautan, Ikatan Mahasiswa Geodesi Institut Teknologi Bandung (ITB). Bandung, 210 hlm.

Mustafa, A., \& Tarunamulia. (2009). Analisis daya dukung lahan tambak berdasarkan pada kuantitas air perairan di sekitar Kecamatan Balusu Kabupaten Barru Provinsi Sulawesi Selatan. Jurnal Riset Akuakultur, 4(3), 395-406.

Parenrengi, A., Rachmansyah, \& Suryati, E. (2011). Budidaya rumput laut : penghasil karaginan (Karaginofit). Balai Riset Perikanan Budidaya Air Payau (BRPBAP) \& Badan Penelitian dan Pengembangan Kelautan dan Perikanan (BPPKP). Jakarta, $54 \mathrm{hlm}$.

Poernomo, A. (1992). Pemilihan lokasi tambak udang berwawasan lingkungan. Badan Penelitian dan Pengembangan Pertanian, Pusat Penelitian dan Pengembangan Perikanan bekerjasama dengan USAID/FRDP. Jakarta, $40 \mathrm{hlm}$.

Purworaharjo, U.U. (1986). Ilmu Ukur Tanah Seri B : Pengukuran tinggi. Jurusan Teknik Geodesi Fakultas Teknik Sipil dan Perencanaan Institut Teknologi Bandung. Bandung, $82 \mathrm{hlm}$.

Radiarta, I N., Erlania, \& Rusman. (2013). Pengaruh iklim terhadap musim tanam rumput laut, Kappaphycus alvarezii di Teluk Gerupuk Kabupaten Lombok Tengah, Nusa Tenggara Barat. Jurnal Riset Akuakultur, 8(3), 453-464.

Tarunamulia, Sammut, J., \& Rachmansyah. (2009). Penilaian kesesuaian perairan untuk budidaya ikan dalam keramba jaring apung berdasarkan model spasial propagasi ombak mendekati pantai. Jurnal Riset Akuakultur, 4(2), 291-306.

Widigdo, B., \& Pariwono, J. (2003). Daya dukung perairan di pantai Utara Jawa Barat untuk budidaya udang (Studi kasus di Kabupaten Subang, Teluk Jakarta, dan Serang). Jurnal Ilmu-Ilmu Perairan dan Perikanan Indonesia, 10(1), 10-17. 